\title{
\begin{tabular}{l|l} 
Mitraries & DSpace@MIT
\end{tabular}
}

\author{
MIT Open Access Articles
}

\section{A Regio- and Enantioselective CuH-Catalyzed Ketone Allylation with Terminal Allenes}

The MIT Faculty has made this article openly available. Please share how this access benefits you. Your story matters.

Citation: Tsai, Erica Y. et al. "A Regio- and Enantioselective CuH-Catalyzed Ketone Allylation with Terminal Allenes." Journal of the American Chemical Society 140, 6 (February 2018): 2007-2011 (C) 2018 American Chemical Society.

As Published: https://dx.doi.org/10.1021/jacs.7b12271

Publisher: American Chemical Society (ACS)

Persistent URL: https://hdl.handle.net/1721.1/125456

Version: Author's final manuscript: final author's manuscript post peer review, without publisher's formatting or copy editing

Terms of Use: Article is made available in accordance with the publisher's policy and may be subject to US copyright law. Please refer to the publisher's site for terms of use. 
J Am Chem Soc. 2018 February 14; 140(6): 2007-2011. doi:10.1021/jacs.7b12271.

\title{
A Regio- and Enantioselective CuH-Catalyzed Ketone Allylation with Terminal Allenes
}

\author{
Erica Y. Tsai, Richard Y. Liu, Yang Yang, and Stephen L. Buchwald ${ }^{\star}$ \\ Department of Chemistry, Massachusetts Institute of Technology, Cambridge, Massachusetts \\ 02139, United States
}

\begin{abstract}
We report a method for the highly enantioselective $\mathrm{CuH}$-catalyzed allylation of ketones that employs terminal allenes as allylmetal surrogates. Ketones and allenes bearing diverse and sensitive functional groups are efficiently coupled with high stereoselectivity and exclusive branched regioselectivity. In stoichiometric experiments, each elementary step of the proposed hydrocupration-addition-metathesis mechanism can be followed by NMR spectroscopy.
\end{abstract}

\section{Graphical Abstract}

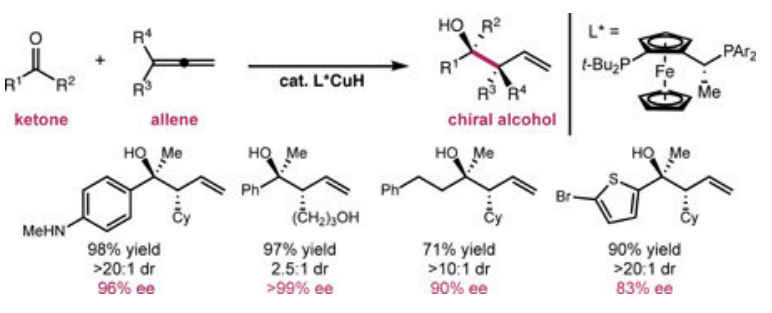

Chiral alcohols and their derivatives are common and essential substructures in biologically active compounds. Thus, reactions that generate alcohols in a stereoselective manner represent fundamental transformations in organic synthesis. In particular, the nucleophilic addition of an allyl group to carbonyl compounds, producing synthetically versatile homoallylic alcohols, has been a subject of extensive investigation. ${ }^{1}$ Despite the invention of several successful implementations, such approaches usually require the prior preparation of superstoichiometric quantities of an allylmetal reagent in a separate operation. ${ }^{2-12}$ Often, this process is itself required to be highly stereoselective in order for the subsequent allylation step to be effective.

Although general solutions exist for simple nucleophiles, such as allyl-, crotyl-, or cinnamyl metal complexes, ${ }^{13}$ practical reagents for installation of complex allyl fragments are rare, and their synthesis typically requires the use of strong bases, restricting compatibility with

\footnotetext{
“Corresponding Author: sbuchwal@mit.edu.

Notes

The authors declare no competing financial interest.

The Supporting Information is available free of charge on the ACS Publications website at DOI: **** Experimental procedures and characterization data for all compounds (PDF)

$\mathrm{X}$-ray diffraction data and analysis for $\mathbf{1 4}$ (PDF, CIF)
} 
acidic or polar functional groups. ${ }^{5}$ As an alternative, we considered a process in which a chiral organometallic reagent assembles catalytically from an olefin and subsequently engages a ketone stereoselectively within a single mechanistic cycle.

Recently, our laboratory has reported several methods involving in situ generation of organocopper nucleophiles via the hydrocupration of unsaturated substrates. ${ }^{14,15}$ Originally developed in the context of hydroamination reactions, ${ }^{151, \mathrm{~m}}$ this hydrometalationfunctionalization strategy has also found success in reductive coupling with carbon-centered electrophiles, most notably imines ${ }^{15 e, f}$ and ketones. ${ }^{15 g}$ In the context of allylation specifically, we were inspired by pioneering work by Krische and others using aldehydes and activated ketones. ${ }^{16-24}$ In general, however, typical ketones are challenging electrophilic partners for stereoselective coupling relative to aldehydes, due to their attenuated reactivity and minimal steric differentiation between the carbonyl substituents.

Our proposal, described in Figure 1B, takes advantage of the ability of phosphine ligated copper hydride complexes to catalytically generate a mixture of allylcopper species when exposed to terminal allenes. ${ }^{11 \mathrm{a}, 11 \mathrm{c}, 11 \mathrm{f}, 15 \mathrm{e}}$ Notably, the rate of this process needed to surpass the rate of direct ketone reduction, which has been shown to be a fast process. ${ }^{24-26}$ Based on theoretical studies on the addition of these nucleophiles to imines, ${ }^{15 \mathrm{e}}$ we anticipated allyl addition to ketones would take place with exclusive branched regioselectivity. ${ }^{15 \mathrm{e}} \mathrm{To}$ complete the catalytic cycle, the initial hydride complex would be regenerated either by direct metathesis with a hydrosilane, or via intermediate ligand exchange with an auxiliary alcohol.

Initial investigations of this transformation were focused on reacting acetophenone (1a) with cyclohexyl-allene (1b) under previously described reaction conditions for imine allylation (Table 1, entry 1). With a simple achiral supporting ligand, the desired product 1 was obtained in high yield, with exclusive branched-selectivity, and with moderate preference for the indicated diastereomer $(5: 1 \mathrm{dr})$. When the ligand was exchanged for chiral phosphine (S,S)-Ph-BPE B, high enantioselectivity was also obtained (Table 1, entry 2). Lowering the reaction temperature slightly and switching the solvent to toluene proved to be beneficial (Table 1, entries 3 and 4). Further evaluation of common chiral ligands revealed JOSIPHOStype phosphine $\mathbf{D}^{27}$ to be optimal (Table 1, entry 7). The effect of tert-butanol on the observed diastereo- and enantioselectivity is notable, although its role remains unclear (Table 1, entry 8 ).

Upon scaling up the optimal conditions to preparative quantities of material, we found that only a small excess of allene (1.2 equiv) and DMMS ( 2 equiv) ${ }^{28}$ were necessary to obtain high yields and selectivity, for instance in the case of model compound 1 (Table 2). The reaction proceeded efficiently with substrates bearing electron-donating $(3,4)$ or electronwithdrawing (6) substituents, although $\mathbf{5}$ was only obtained in moderate yield.

Acetophenones bearing ortho-substituents were converted successfully, as well as symmetrical (9) or cyclic (10) ketones. Furthermore, substrates containing heterocycles (1114) and those with functional groups such as a free hydroxyl group (4), a secondary amine $(\mathbf{3})$, aryl halides $(\mathbf{6}, \mathbf{1 2})$, a sulfonyl protecting group (14), and tert-butyl ester (5) were all tolerated under the reaction conditions, providing opportunities for further elaboration. 
Finally, dialkyl ketone 15 was converted, notably with high diastereoselectivity considering the steric similarity of the methyl and methylene substituents on the ketone. In all cases, the reaction proceeded with useful to good enantioselectivity. A crystal structure of $\mathbf{1 4}$ showed the absolute configuration of the major enantiomer to be $(S)$ at the tetrasubstituted stereocenter and $(R)$ at the adjacent methane. We note that the relative configuration of these stereocenters is consistent with addition through a chair-like 6-membered transition state.

We next assessed the scope of compatible allenes under these conditions. Unbranched (16) and 1,1-disubstituted (17) allenes are both coupled with high enantioselectivity. A commercial ether, methoxyallene, was employed effectively as a precursor for an (alkoxy)allylmetal nucleophile (18), which is rarely utilized in ketone additions even when prepared stoichiometrically. Various polar functional groups are tolerated well on the allene component, including an alcohol (19), an ester (20), and a secondary amide (21). An allene bearing a nitrogen heterocycle (22) reacted efficiently and with a high level of enantioselectivity. Under current conditions, however, addition of the parent allyl fragment derived from allene gas proceeds with only moderate selectivity $(\mathbf{2 3})$.

We also carried out a number of experiments by NMR to corroborate the plausibility of our mechanistic proposal (Scheme 1). For the purpose of these studies, we chose the achiral, but kinetically competent ligand DCyPE (A) for these studies.

The putative copper hydride complex was prepared stoichiometrically by addition of 1.0 equivalent of DMMS to phosphine ligated copper(I) acetate complex I. From here, addition of excess cyclohexylallene led to insertion, forming complex II with spectroscopic properties consistent with that of a linear allyl copper species (based on ${ }^{1} \mathrm{H}$ and ${ }^{31} \mathrm{P}$ NMR spectroscopy, see Supporting Information). The observed linear allylcopper complex also has been previously predicted by DFT studies to be the lowest energy isomer. ${ }^{15 \mathrm{e}} \mathrm{As}$ expected, addition of excess acetophenone resulted in insertion to form the copper-alkoxide complex III of the desired tertiary alcohol product. This complex can be reconverted into the initial hydride complex I directly upon addition of an excess of hydrosilane. Having observed each of the proposed intermediates by ${ }^{31} \mathrm{P}$ NMR spectroscopy, we aimed to determine the resting state of the copper catalyst under the standard reaction conditions. Examination of the reaction mixture by ${ }^{31} \mathrm{P}$ NMR spectroscopy during a catalytic reaction starting with DCyPE-ligated copper hydride complex I revealed a single resonance at 10.7 ppm matching the chemical shift of the copper allyl species II. Thus, we conclude that the catalyst is predominantly present in the allylcopper form under the typical reaction conditions. Therefore, since we propose that addition to the ketone is irreversible and stereoselectivity-determining, we suggest that this step is also turnover-limiting.

In summary, we have developed a mild, base-metal-catalyzed asymmetric allylation of ketones from terminal allenes. We anticipate that the chemoselective hydrocupration-1,2addition sequence demonstrated here will serve as a platform for the development of further synthetically useful transformations of unsaturated compounds. 


\section{Supplementary Material}

Refer to Web version on PubMed Central for supplementary material.

\section{Acknowledgments}

Research reported in this publication was supported by the National Institutes of Health (GM122483, GM46059, GM058160-17S1). The content of this communication solely reflects the research and opinion of the authors and does not necessarily represent the official views of the NIH. Solvias AG is acknowledged for a generous gift of SLJ011-1. E.Y.T. and R.Y.L. thank MIT for Presidential Graduate Fellowships. R.Y.L. also acknowledges BristolMyers Squibb for a Fellowship in Synthetic Organic Chemistry. We are grateful to Dr. Charlene Tsay for X-ray crystallographic analysis and to Drs. Andy Thomas, Mycah Uehling, and Christine Nguyen for advice on the preparation of this manuscript.

\section{References}

1. For selected recent reviews describing stereoselective allyl addition to carbonyl compounds, see: Huo HX, Duvall JR, Huang MY, Hong R. Org Chem Front. 2014; 1:303. Yus M, Gonzalez-Gomez JC, Foubelo F. Chem Rev. 2013; 113:5595. [PubMed: 23540914] Yus M, Gonzalez-Gomez JC, Foubelo F. Chem Rev. 2011; 111:7774. [PubMed: 21923136] Tietze LF, Kinzel T, Brazel CC. Acc Chem Res. 2009; 42:367. [PubMed: 19154154] Shibasaki M, Kanai M. Chem Rev. 2008; 108:2853. [PubMed: 18570481] Hatano M, Ishihara K. Synthesis. 2008; 11:1647.Yamamoto H, Wadamoto M. Chem Asian J. 2007; 2:692. [PubMed: 17523136] Denmark SE, Fu J. Chem Rev. 2003; 103:2763. [PubMed: 12914480]

2. For examples of catalytic, asymmetric addition of allylboron reagents to ketones, see: Robbins DW, Lee K, Silverio DL, Volkov A, Torker S, Hoveyda AH. Angew Chem Int Ed. 2016; 55:9610.Lee K, Silverio DL, Torker S, Haeffner F, Robbins DW, van der Mei FW, Hoveyda AH. Nat Chem. 2016; 8:768. [PubMed: 27442282] Alam R, Volgraff T, Eriksson L, Szabo KJ. J Am Chem Soc. 2015; 137:11262. [PubMed: 26316158] Zhang Y, Li N, Qu Bo, Ma S, Lee H, Gonnella NC, Gao J, Li W, Tan Z, Reeves JT, Wan J, Lorenz JC, Li G, Reeves DC, Premasiri A, Grinberg N, Haddad N, Lu BZ, Song JJ, Senanayake CH. Org Lett. 2013; 15:1710. [PubMed: 23527954] Lou S, Moquist PN, Schaus SE. J Am Chem Soc. 2006; 128:12660. [PubMed: 17002355]

3. For examples of catalytic, asymmetric addition of allylmetal reagents to ketones using copper catalysts, see: Shi SL, Xu LW, Oisaki K, Kanai M, Shibasaki M. J Am Chem Soc. 2010; 132:6638. [PubMed: 20420398] Kanai M, Wada R, Shibuguchi T, Shibasaki M. Pure Appl Chem. 2008; 80:1055.Wada R, Oisaki K, Kanai M, Shibasaki M. J Am Chem Soc. 2004; 126:8910. [PubMed: 15264818] Yamasaki S, Fujii K, Wada R, Kanai M, Shibasaki M. J Am Chem Soc. 2002; 124:6536. [PubMed: 12047165]

4. For examples of catalytic, asymmetric addition of allylmetal reagents to ketones using titanium catalysts, see: Yadav J, Stanton GR, Fan X, Robinson JR, Schelter EJ, Walsh PJ, Pericas MA. Chem Eur J. 2014; 20:7122. [PubMed: 24737394] Barnett DS, Moquist PN, Schaus SE. Angew Chem Int Ed. 2009; 48:8679.Wooten AJ, Kim JG, Walsh PJ. Org Lett. 2007; 9:381. [PubMed: 17249767] Kii S, Maruoka K. Chirality. 2003; 15:68. [PubMed: 12467045]

5. For examples of catalytic, asymmetric addition of allylmetal reagents to ketones using indium catalysts, see: Zhang X, Chen D, Liu X, Feng X. J Org Chem. 2007; 72:5227. [PubMed: 17559275] Teo YC, Goh JD, Loh TP. Org Lett. 2005; 7:2743. [PubMed: 15957936]

6 . For an example of a catalytic, asymmetric addition of allylmetal reagents to ketones using a scandium catalyst, see: Hanhan NV, Tang YC, Tran NT, Franz AK. Org Lett. 2012; 14:2218. [PubMed: 22506841]

7. For an example of a catalytic, asymmetric addition of allylmetal reagents to ketones using a silver catalyst, see: Wadamoto M, Yamamoto H. J Am Chem Soc. 2005; 127:14556. [PubMed: 16231892]

8. For examples of catalytic, asymmetric addition of allyl halide reagents to ketones using stoichiometric reductant and chromium catalysts, see: Chen R-Y, Dohndge AP, Lee G-H, Chen C. Adv Synth Catal. 2015; 357:961.Huang XR, Chen C, Lee GH, Peng SM. Adv Synth Catal. 2009; 351:3089.Miller JJ, Sigman MS. Angew Chem Int Ed. 2008; 47:771.Miller JJ, Sigman MS. J Am Chem Soc. 2007; 129:2752. [PubMed: 17309263] 
9. For an example of a catalytic, asymmetric addition of allyl halide reagents to ketones using stoichiometric reductant and an indium catalyst, see: Shen Z-L, Wang S-Y, Chok Y-K, Xu Y-H, Loh T-P. Chem Rev. 2013; 113:271. [PubMed: 23110495]

10. For reviews detailing catalytic, asymmetric, nucleophilic allylation reactions that circumvent the generation of stoichiometric allylmetal species, see: Semba K, Fujihara T, Terao J, Tsuji Y. Tetrahedron. 2015; 71:2183.Jeganmohan M, Cheng C-H. Chem Commun. 2008:3101.

11. For examples of catalytic, asymmetric, nucleophilic allylation reactions that circumvent the generation of stoichiometric allylmetal species using copper catalysts, see: Lee M, Nguyen M, Brandt C, Kaminsky W, Lalic G. Angew Chem Int Ed. 2017; 56:15703.Boreux A, Indukuri K, Gagosz F, Riant O. ACS Catal. 2017; 7:8200.Pulis AP, Yeung K, Procter DJ. Chem Sci. 2017; 8:5240. [PubMed: 28959423] Yeung K, Ruscoe RE, Rae J, Pulis AP, Procter DJ. Angew Chem Int Ed. 2016; 55:11912.Muller DS, Marek I. Chem Soc Rev. 2016; 45:4552. [PubMed: 26808300] Tani Y, Kuga K, Fujihara T, Terao J, Tsuji Y. Chem Commun. 2015; 51:13020.Chikkade PK, Shimizu Y, Kanai M. Chem Sci. 2014; 5:2013.Kawai J, Chikkade PK, Shimizu Y, Kanai M. Angew Chem Int Ed. 2013; 52:7177.Meng F, Jang H, Jung B, Hoveyda AH. Angew Chem Int Ed. 2013; 52:5046.Galestokova Z, Sebest R. Eur J Org Chem. 2012; 34:6688.Oisaki K, Zhao D, Kanai M, Shibasaki M. J Am Chem Soc. 2007; 129:7439. [PubMed: 17503823]

12. For examples of transfer hydrogenative carbonyl allylations of allyl acetate using iridium catalysts, see: Kim IS, Ngai MY, Krische MJ. J Am Chem Soc. 2008; 130:6340. [PubMed: 18444616] Kim IS, Ngai MY, Krische MJ. J Am Chem Soc. 2008; 130:14891. [PubMed: 18841896]

13. For representative methods for preparation of crotyl, prenyl, or substituted cinnamyl metal reagents, see: Huber JD, Perl NR, Leighton JL. Angew Chem Int Ed. 2008; 47:3037.Brown HC, Jadhav PK. Tet Lett. 1984; 25:1215.Schlosser M, Rauchschwalbe G. J Am Chem Soc. 1978; 100:3258.

14. For reviews, see: Pirnot MT, Wang YM, Buchwald SL. Angew Chem Int Ed. 2016; 55:48.Mohr J, Oestreich M. Angew Chem Int Ed. 2016; 55:12148.

15. For selected examples, see: Zhou Y, Bandar JS, Buchwald SL. J Am Chem Soc. 2017; 139:8126. [PubMed: 28565905] Friis SD, Pirnot MT, Dupuis LN, Buchwald SL. Angew Chem Int Ed. 2017; 56:7242.Gribble MW, Pirnot MT, Bandar JS, Liu RY, Buchwald SL. J Am Chem Soc. 2017; 139:2192. [PubMed: 28117996] Friis SD, Pirnot MT, Buchwald SL. J Am Chem Soc. 2016; 138:8372. [PubMed: 27346525] Liu RY, Yang Y, Buchwald SL. Angew Chem Int Ed. 2016; 55:14077. Yang Y, Perry IB, Buchwald SL. J Am Chem Soc. 2016; 138:9787. [PubMed: 27454393] Yang Y, Perry IB, Lu G, Liu P, Buchwald SL. Science. 2016; 353:144. [PubMed: 27284169] Wang YM, Buchwald SL. J Am Chem Soc. 2016; 138:5024. [PubMed: 27042864] Yang Y, Shi SL, Liu P, Buchwald SL. Science. 2015; 349:62. [PubMed: 26138973] Ascic E, Buchwald SL. J Am Chem Soc. 2015; 137:4666. [PubMed: 25826004] Saxena A, Choi B, Lam HW. J Am Chem Soc. 2012; 134:8428. [PubMed: 22563725] For the earliest examples of CuH catalyzed hydroamination, see: Miki Y, Hirano K, Satoh T, Miura M. Angew Chem, Int Ed. 2013; 52:10830.Zhu S, Niljianskul N, Buchwald SL. J Am Chem Soc. 2013; 135:15746. [PubMed: 24106781]

16. For reviews, see: Nguyen KD, Park BY, Luong T, Sato H, Garza VJ, Kirsche MJ. Science. 2016; 354:300.Hassan A, Krische MJ. Org Proc Res Dev. 2011; 15:1236.

17. For selected examples using iridium catalysts, see: Bower JF, Krische MJ. Top Organomet Chem. 2011; 34:107. [PubMed: 21822399] Bower JF, Patman RL, Krische MJ. Org Lett. 2008; 10:1033. [PubMed: 18254642]

18. For selected examples using ruthenium catalysts, see: Nguyen KD, Herkommer D, Krische MJ. J Am Chem Soc. 2016; 138:5238. [PubMed: 27079149] Zbieg JR, Yamaguchi E, McInturff EL, Krische MJ. Science. 2012; 336:324. [PubMed: 22442385] Leung JC, Geary LM, Chen TY, Zbeig JR, Krische MJ. J Am Chem Soc. 2012; 134:15700. [PubMed: 22985393] Zbeig JR, Moran J, Krische MJ. J Am Chem Soc. 2011; 133:10582. [PubMed: 21627316]

19. For a selected example using a zirconium catalyst, see: Schwartz LA, Krische MJ. Isr J Org Chem. 2017; 82:5981.

20. For a selected example using a rhodium catalyst, see: Komanduri V, Krische MJ. J Am Chem Soc. 2006; 128:16448. [PubMed: 17177363] 
21. For examples of reductive couplings of carbonyls and allenes using iridium catalysts, see: Holmes M, Nguyen KD, Schwartz LA, Luong T, Krische MJ. J Am Chem Soc. 2017; 139:8114. [PubMed: 28603973] Moran J, Preetz A, Mesch RA, Krische MJ. Nature Chem. 2011; 3:287. [PubMed: 21430686] Han SB, Kim IS, Han H, Krische MJ. J Am Chem Soc. 2009; 131:6916. [PubMed: 19453190] Bower JF, Skucas E, Patman RL, Krische MJ. J Am Chem Soc. 2007; 129:15134. [PubMed: 18020342] Skucas E, Bower JF, Krische MJ. J Am Chem Soc. 2007; 129:12678. [PubMed: 17900123]

22. For examples of reductive couplings of carbonyls and allenes using ruthenium catalysts, see: Sam B, Luong T, Krische MJ. Angew Chem Int Ed. 2015; 54:5465.Oda S, Sam B, Krische MJ. Angew Chem Int Ed. 2015; 54:8525.Sam B, Montgomery TP, Krische MJ. Org Lett. 2013; 15:3790. [PubMed: 23841678] Zbieg JR, McInturff EL, Leung JC, Krische MJ. J Am Chem Soc. 2011; 133:1141. [PubMed: 21175178] Zbieg JR, McInturff EL, Krische MJ. Org Lett. 2010; 12:2514. [PubMed: 20459077] Skucas E, Zbieg JR, Krische MJ. J Am Chem Soc. 2009; 131:5054. [PubMed: 19317402] Ngai MY, Skucas E, Krische MJ. Org Lett. 2008; 10:2705. [PubMed: 18533665]

23. For examples of reductive couplings of carbonyls and allenes using nickel catalysts, see: $\mathrm{Ng} \mathrm{SS}$, Jamison TJ. Tetrahedron. 2006; 62:11350.Song M, Montgomery J. Tetrahedron. 2005; 61:11440.Ng SS, Jamison TJ. Tetrahedron. 2005; 61:11405.Ng SS, Jamison TJ. J Am Chem Soc. 2005; 127:7320. [PubMed: 15898774]

24. For examples of reductive couplings of carbonyls and alkynes as latent allenes, see: Liang $\mathrm{T}$, Nguyen KD, Zhang W, Krische MJ. J Am Chem Soc. 2015; 137:3161. [PubMed: 25734220] Park BY, Nguyen KD, Chaulagain MR, Komanduri V, Krische MJ. J Am Chem Soc. 2014; 136:11902. [PubMed: 25075434]

25. For a selected review of 1,2-reduction reactions catalyzed by ligated $\mathrm{CuH}$, see: Deutsch $\mathrm{C}$, Krause N, Lipshutz BH. Chem Rev. 2008; 108:2916. [PubMed: 18616323]

26. For selected examples of 1,2-reduction reactions catalyzed by ligated $\mathrm{CuH}$, see: Moser R, Boskovic ZV, Crowe CS, Lipshutz BH. J Am Chem Soc. 2010; 132:7852. [PubMed: 20481528] Voigtritter KR, Isley NA, Moser R, Aue DH, Lipshutz BH. Tetrahedron. 2012; 68:3410.Shi SL, Wong ZL, Buchwald SL. Nature. 2016; 532:353. [PubMed: 27018656] Malkov AV. Angew Chem, Int Ed. 2010; 49:9814.Gallagher BD, Taft BR, Lipshutz BH. Org Lett. 2009; 11:5374. [PubMed: 19877705] Waidmann CR, Silks LA, Wu R, Gordon JC. Catal Sci Technol. 2013; 3:1240.

27. Blaser HU, Brieden W, Pugin B, Spindler F, Studer M, Togni A. Top Cat. 2002; 19:3.

28. For detailed information on the safe handling of DMMS, please refer to the Supporting Information. 
A Traditional asymmetric allylation of carbonyl compounds using allyl metal reagents

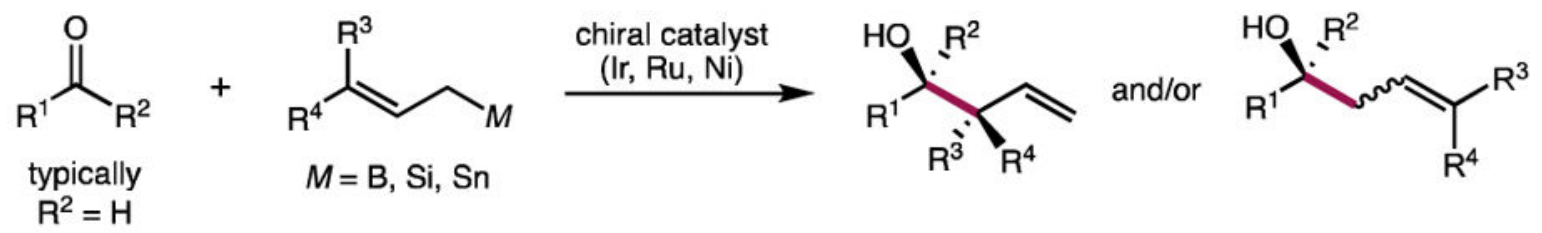

B This work: catalytic allylation using allenes as organometal surrogates

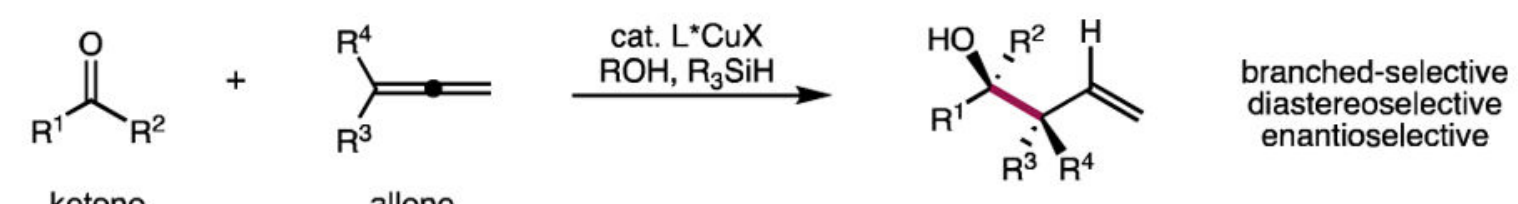
ketone allene

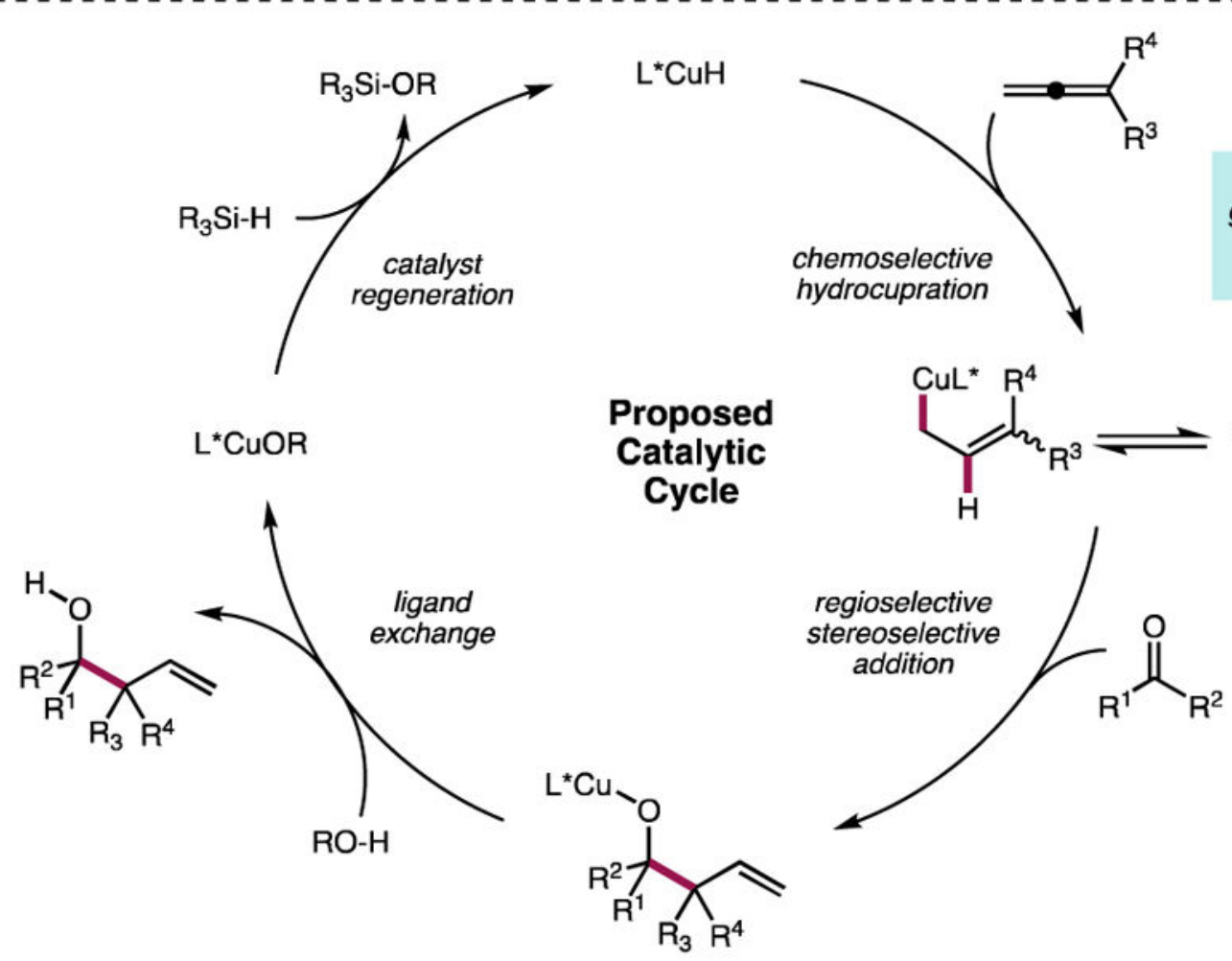

Figure 1.

Overview of metal-catalyzed reductive allylation reaction of ketones using terminal allenes. 


$$
\delta=4.2 \mathrm{ppm} \quad \delta=15.8 \mathrm{ppm}
$$

(a)

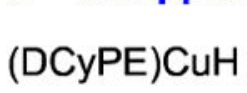

(b)

$$
\delta=10.7 \mathrm{ppm}
$$

(DCyPE)CuOAc
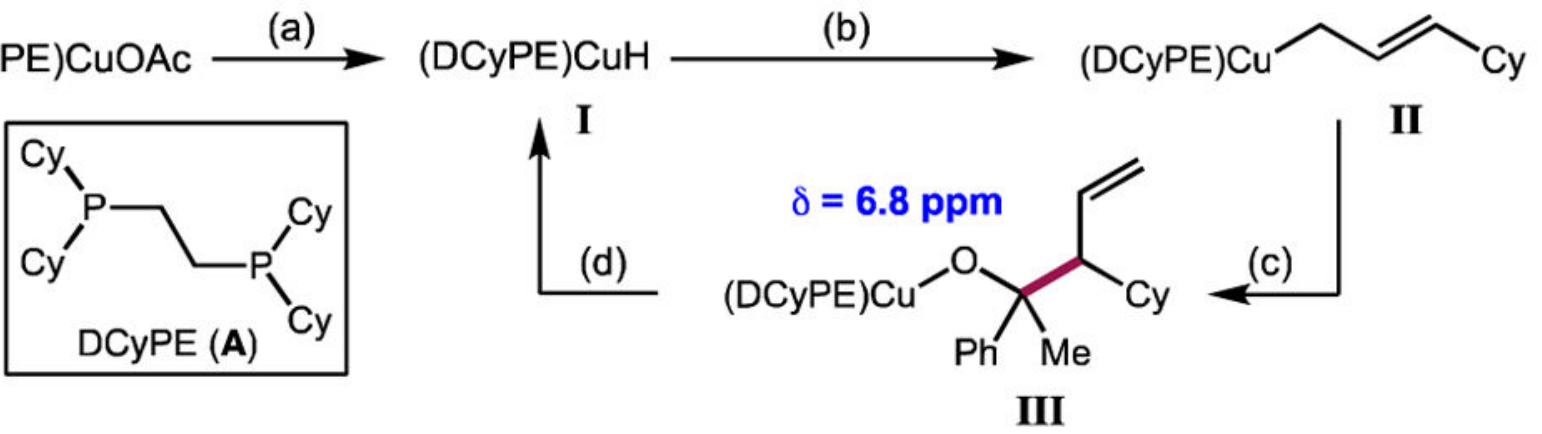

Scheme 1. Stoichiometric Observation of Relevant Reaction Intermediates by ${ }^{31}$ P NMR Spectroscopy

Quantities shown in blue are chemical shifts of the phosphorus atoms in major species shown; see Supporting Information for details. (a) $(\mathrm{MeO})_{2} \mathrm{MeSiH}$, benzene; (b) cyclohexylallene, benzene; (c) acetophenone, benzene; (d) $(\mathrm{MeO})_{2} \mathrm{MeSiH}$. 


\section{Table 2}

\section{Evaluation of Ketone Scope.}

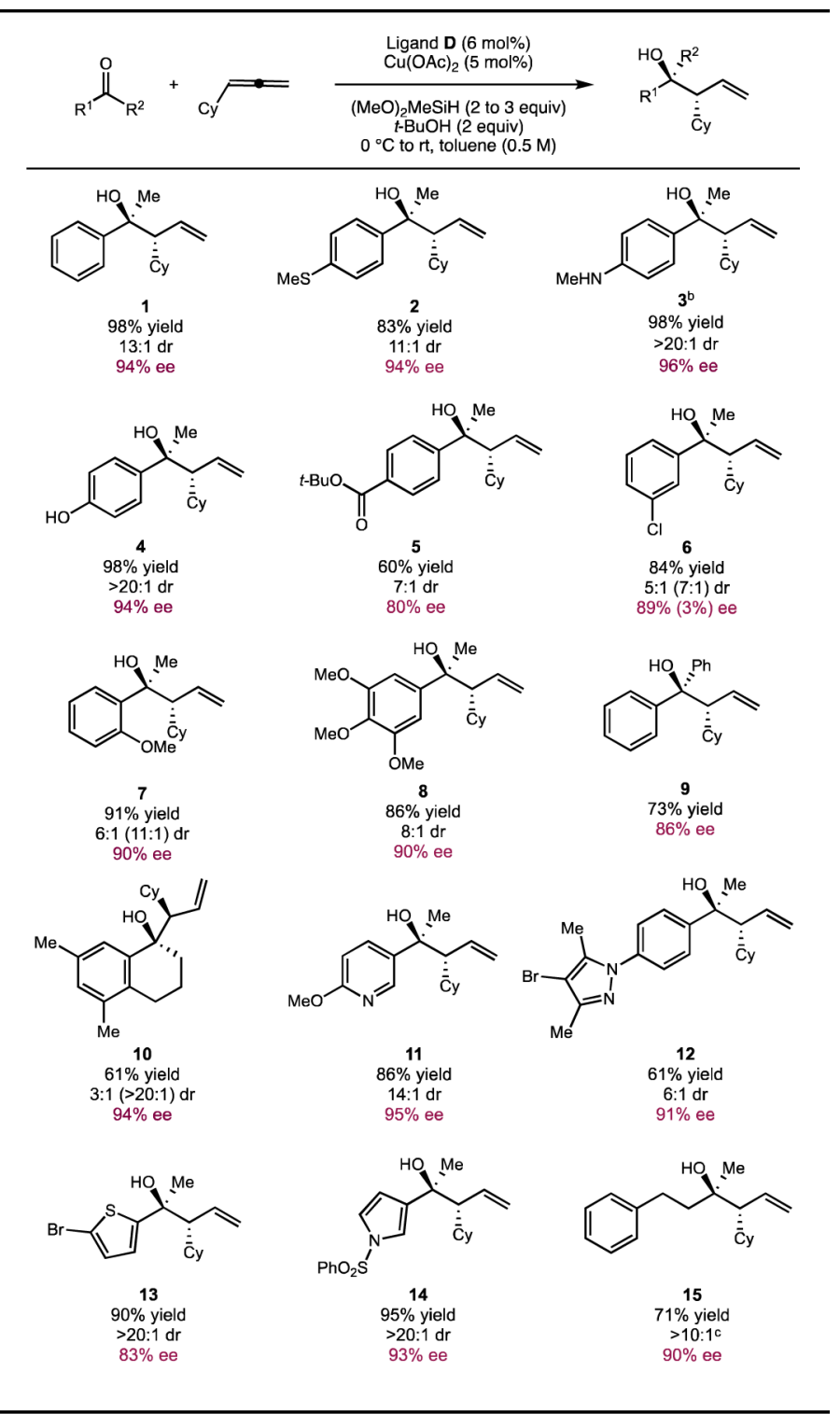

${ }^{a}$ Yields indicate isolated yield of product as a mixture of two diastereomers on a $0.5 \mathrm{mmol}$ scale. 1.2 equiv of allene was used, see Supporting Information for further details. Diastereomeric ratios were determined by ${ }^{1} \mathrm{H}$ NMR spectroscopy for both the crude and purified products using 1,1,2,2-tetrachloroethane as internal standard;. Enantiomeric excesses determined by HPLC or SFC analysis on commercial chiral columns; enantiomeric ratios of minor diastereomers indicated in parentheses. Yields, diastereomeric ratios, and enantiomeric excesses are the averages for two identical runs.

$b_{\text {The reaction was conducted without tert-butanol; }}$

$c^{c}$ The diastereomeric ratio was determined using both GC and chiral SFC analysis. 
Table 3

Evaluation of Allene Scope. ${ }^{a}$

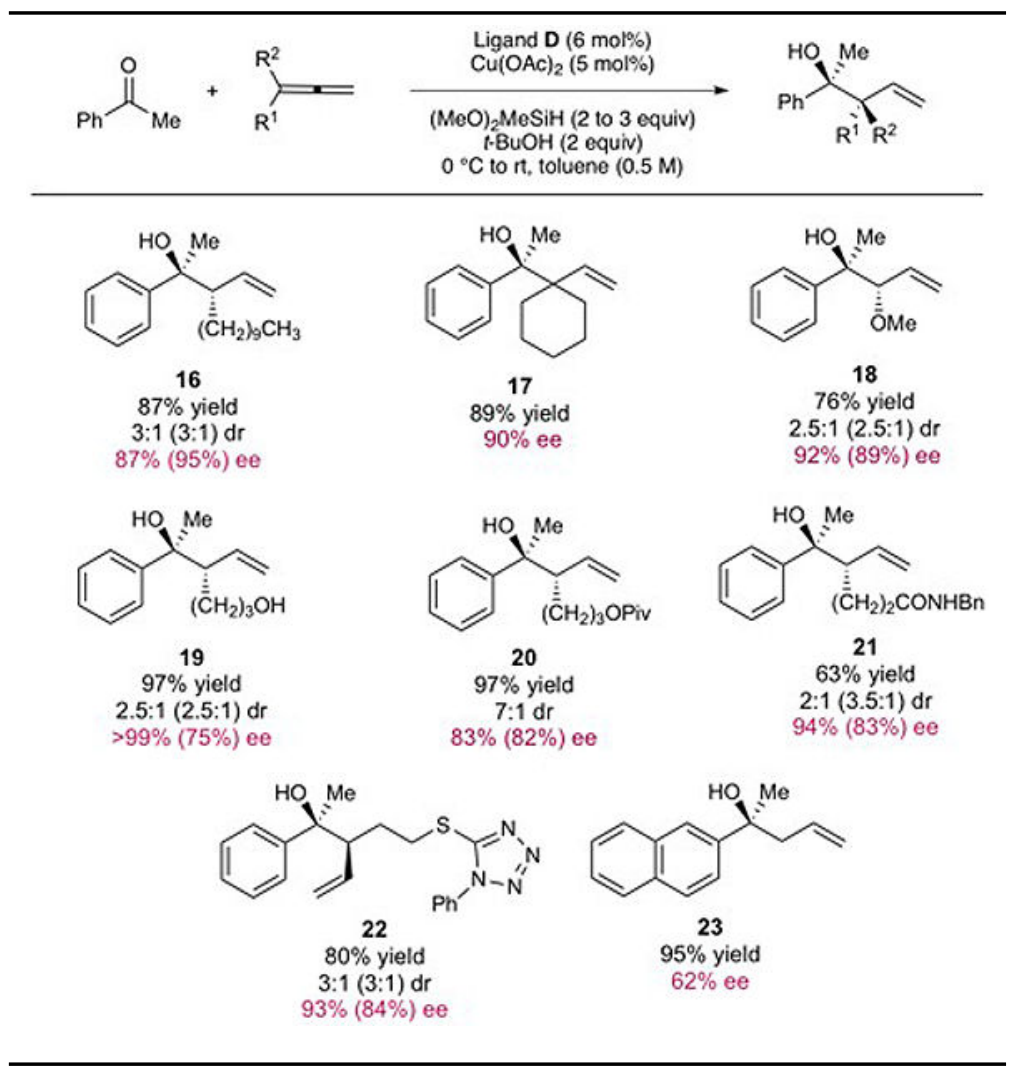

${ }^{a}$ Yields indicate isolated yield of product as a mixture of two diastereomers on a $0.5 \mathrm{mmol}$ scale, unless otherwise indicated. 1.2 equiv of allene was used, see Supporting Information for further details. Diastereomeric ratios determined by ${ }^{1} \mathrm{H}$ NMR spectroscopy of the crude mixture, using 1,1,2,2-tetrachloroethane as internal standard. Enantiomeric excesses determined by HPLC or SFC analysis on commercial chiral columns; enantiomeric ratios of minor diastereomers indicated in parentheses. Yields, diastereomeric ratios, and enantiomeric excesses are the averages for two identical runs.

$b_{\text {The reaction was conducted on a } 0.1 \mathrm{mmol} \text { scale. }}$ 